\title{
System Dynamic Simulation of Knowledge Management Based on Financial Service Innovation: A Case Study of Shanghai FTZ
}

\author{
Shenghua XU \\ School of Information Management \\ Jiangxi University of Finance and Economics \\ Nanchang, China \\ e-mail: jxcdxsh@foxmail.com
}

\author{
Jinzhu JIANG \\ School of Information Management \\ Jiangxi University of Finance and Economics \\ Nanchang, China \\ e-mail: emmajiang0629@foxmail.com
}

\begin{abstract}
In order to enhance the advantages of financial service innovation for state-owned commercial banks in Shanghai Free Trade Zone, this paper puts forward the conceptual model of knowledge management in financial service innovation, analyze the influence factors of knowledge management for state-owned commercial banks in financial services innovation. A knowledge management system dynamics quantitative model based on financial service innovation was built with Vensim PLE, and the validity of the model has been verified. The results show that the model can better fit the process of knowledge management in financial service innovation activities, and conclude the influence degree of each factor in knowledge creation, knowledge sharing and knowledge application stage.
\end{abstract}

Keywords-financial service innovation; Shanghai FTZ; knowledge management; system dynamics

\section{INTRODUCTION}

With the development of "Internet plus", the integration of traditional industries and Internet technology has gradually become a new form of social development in knowledge innovation, of which the most significant is the integration of the Internet and the financial services industry. As a typical knowledge intensive industry, financial service industry has a high degree of interactivity and liquidity [1], which improves the knowledge management requirements of enterprises. Shanghai Free Trade Zone (FTZ), for example, since its establishment in September 2013, the overall financial service innovation achievement is significant, with the main innovative product still drew lessons from foreign banks [2]. The single operation mode of the state-owned commercial bank lacks of knowledge management experience in the international environment. Accompanied by the policies of marketization of interest rate and financial liberalization which exacerbated the degree of marketization of the external environment, the state-owned commercial banks are facing with more severe challenges. Previous studies mostly focused on the characteristics, classification, process of financial service innovation, which ignored the industry's high knowledge intensive characteristic itself [3]. The establishment of free trade zone like Shanghai and other areas highlighted the importance and necessity of knowledge management in the financial services industry. Therefore, it has certain theoretical innovation and practical significance to regard the related factors and their relations in financial service innovation of knowledge management as a research subject, to analyze internal main factors and ways of action in the process of innovation.

\section{CONCEPTUAl Model}

\section{A. The Characteristics of the Banking Industry in Shanghai FTZ}

The environment of banking industry in Shanghai FTZ is different from the one of traditional commercial bank market. The participation of Foreign Exchange Administration, the CBRC, foreign banks and many other institutions makes it a broader business scope and higher market internationalization degree [4]. From the aspect of the stateowned commercial banks, the characteristics can be summarized as the following four points:

1) Rival diversification: Foreign banks with diverse business types occupy a large part in the region of the commercial banks.

2) Business scope integration: RMB Cross-Border Use, Offshore Business and other policies help the commercial banks get rid of the traditional policy restrictions and broaden the scope of services.

3) Customer diversification: On the basis of traditional customers, there are more types of customer groups like joint venture financial institutions, foreign financial institutions, as well as overseas individuals.

4) Technology internationalization: International partners and competitors provide new impetuses and platforms to enhance the level of business technology.

\section{B. Conceptual Model of Knowledge Management Based on Financial Service Innovation}

The characteristics of the banking industry in Shanghai FTZ can be summarized as rival diversification, business scope integration, customer diversification and technology internationalization. Under this background, we combined the activities in knowledge management with that of financial service innovation process, considering the process starts from knowledge creation, transferring by knowledge sharing, with the purpose of knowledge application [5]. However, the influence factors and mechanism of knowledge management are different at each stages. 


\section{1) Knowledge creation phase}

In the phase of knowledge creation, financial enterprises transfer knowledge and update their own knowledge base by interacting with different knowledge subjects (partners, competitors, customers, etc.). In this process, the main factors affecting the performance of financial service innovation are: knowledge resource stock, resource dependence degree and organizational learning ability. Knowledge resource stock is the source of innovation for commercial banks. Resource dependence degree determines the degree of interaction with the external subjects. Organizational learning ability is the embodiment of the enterprises' capacity to absorb internal knowledge [6]. According to the industry characteristics of Shanghai FTZ, the above factors were analyzed specifically:

- The factors that mainly influenced knowledge resources stock include the ability of international competitor intelligence collecting, customer needs perception [7], new policy perception. These three factors reflect the emerging requirements from competitors, customers and policy environment on the level of knowledge management in the new environment, which determine the ability of financial enterprises to acquire new knowledge.

- The factors that mainly influenced knowledge resources stock include the ability of international competitor intelligence collecting, customer needs perception [7], new policy perception. These three factors reflect the emerging requirements from competitors, customers and policy environment on the level of knowledge management in the new environment, which determine the ability of financial enterprises to acquire new knowledge.

- Organizational learning ability is mainly determined by enterprise's own mechanism, which has a direct impact on financial service innovation performance.

\section{2) Knowledge sharing phase}

In the phase of knowledge sharing, it mainly includes the knowledge communication between innovation team and subjects inside or outside of the enterprise. the innovation team of the financial enterprise and the external and internal employees. From the perspective of enterprise, the controllable subjects are individual employees and enterprise environment. The process of knowledge sharing can be considered as the process of knowledge extraction from individual knowledge to organizational knowledge, therefore the knowledge level of individual employee directly affects the knowledge value of knowledge financial service innovation [9]. At the same time, a good atmosphere of knowledge sharing is conducive to the knowledge interaction and circulation between employees, which can promote the development of service innovation.

\section{3) Knowledge application phase}

In the stage of knowledge application, it is necessary to apply the new knowledge to the service development process through appropriate technology and platform. Therefore, the technical factors are very important at this stage, which mainly include the ability of enterprise to perceive the new technology and its own information processing mechanism. Good sense of new technology ensures the efficiency in enterprise knowledge application by avoiding redundant information and improving the speed of knowledge dissemination, which are conducive to the building of efficient financial service platform [10]. An appropriate mechanism of information processing is the basic guarantee of enterprise information transmission, decision support and communication technology, which provides the technical foundation for the application of new service.

Based on the analysis of the above three phases, the conceptual model of knowledge management based on financial service innovation is summarized (Fig. 1).

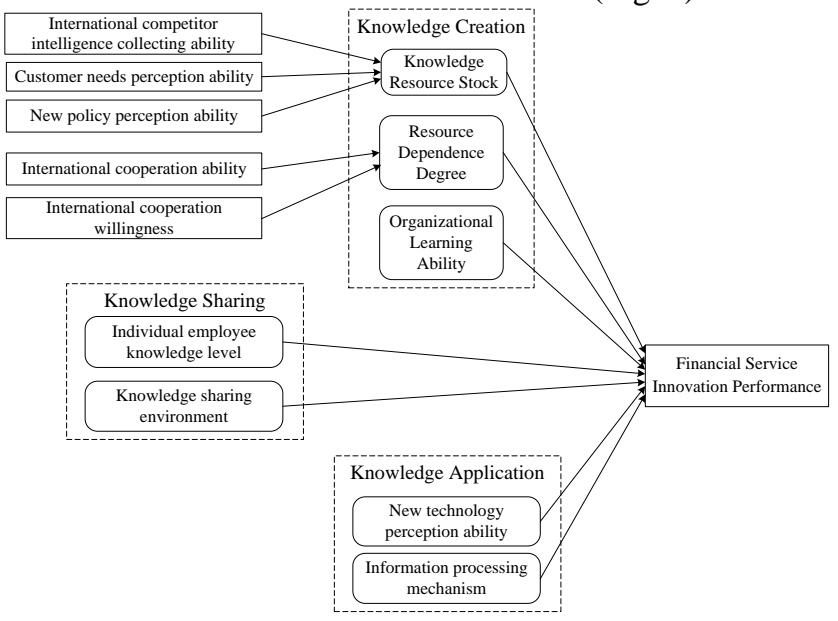

Figure 1. Conceptual model of knowledge management based on financial service innovation.

\section{Quantitative Model}

In order to research the process of knowledge management in financial service innovation, the System Dynamics(SD) method was introduced to construct a quantitative model, based on the conceptual model. System Dynamics is a method to quantitatively reflect the dynamic mechanism of the system by computer simulation technology. The main determining factor lies in the feedback structure among the elements of the system, which is not sensitive to the parameters. Because of the abstraction and complexity in knowledge management process, some of the data is difficult to quantify, so the SD method can be used to research the process.

\section{A. Model Assumption}

Before constructing the model, it is necessary to make a series of assumptions about the operating environment, so as to attach practical significance to the model, as well as avoiding low precision of the model caused by the inaccurate description of some details. Based on above discussion, the following assumptions were drawn:

- There is no distinction between the participants in the whole process of financial services innovation.

- In the process of system operation, there is no system collapse caused by bad external environment. 
- The knowledge transfer ability of the enterprise can be regarded as approximately equal to each other.

\section{B. Causality Analysis of Knowledge Management Based on Financial Service Innovation}

The final behavior of the SD method is determined by the causal relation between the elements. According to the conceptual model of knowledge creation, sharing and application stages, the corresponding system is divided into three subsystems: knowledge creation subsystem, knowledge development subsystem and knowledge application subsystem based on financial service innovation. The causality diagrams of each subsystem are shown in Fig. 2Fig. 4.

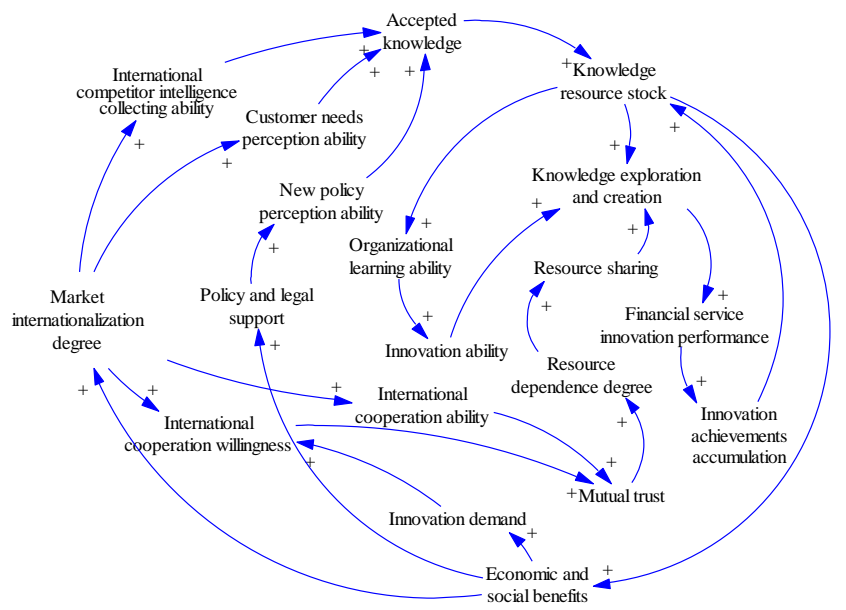

Figure 2. Causality diagram of knowledge creation subsystem based on Financial Service Innovation.

As can be seen in Fig. 2, the main feedback loops in the causality diagram are:

- Knowledge resource stock $\rightarrow$ economic and social benefits $\rightarrow$ market internationalization degree $\rightarrow$ international competitor intelligence collecting ability $\rightarrow$ accepted knowledge $\rightarrow$ knowledge resource stock.

- Knowledge resource stock $\rightarrow$ economic and social benefits $\rightarrow$ policy and legal support $\rightarrow$ new policy perception ability $\rightarrow$ accepted knowledge $\rightarrow$ knowledge resource stock.

- Knowledge resource stock $\rightarrow$ economic and social benefits $\rightarrow$ market internationalization degree $\rightarrow$ customer needs perception ability $\rightarrow$ accepted knowledge $\rightarrow$ knowledge resource stock.

- Knowledge resource stock $\rightarrow$ organizational learning ability $\rightarrow$ innovation ability $\rightarrow$ knowledge exploration and creation $\rightarrow$ financial service innovation performance $\rightarrow$ innovation achievements accumulation $\rightarrow$ knowledge resource stock.

- Knowledge resource stock $\rightarrow$ economic and social benefits $\rightarrow$ innovation demand $\rightarrow$ international cooperation willingness $\rightarrow$ mutual trust $\rightarrow$ resource dependence degree $\rightarrow$ resource sharing $\rightarrow$ knowledge exploration and creation $\rightarrow$ financial service innovation performance $\rightarrow$ innovation achievements accumulation $\rightarrow$ knowledge resource stock.

- Knowledge resource stock $\rightarrow$ economic and social benefits $\rightarrow$ market internationalization degree $\rightarrow$ international cooperation willingness $\rightarrow$ mutual trust $\rightarrow$ resource dependence degree $\rightarrow$ resource sharing $\rightarrow$ knowledge exploration and creation $\rightarrow$ financial service innovation performance $\rightarrow$ innovation achievements accumulation $\rightarrow$ knowledge resource stock.

- Knowledge resource stock $\rightarrow$ economic and social benefits $\rightarrow$ market internationalization degree $\rightarrow$ international cooperation ability $\rightarrow$ mutual trust $\rightarrow$ resource dependence degree $\rightarrow$ resource sharing $\rightarrow$ knowledge exploration and creation $\rightarrow$ financial service innovation performance $\rightarrow$ innovation achievements accumulation $\rightarrow$ knowledge resource stock.

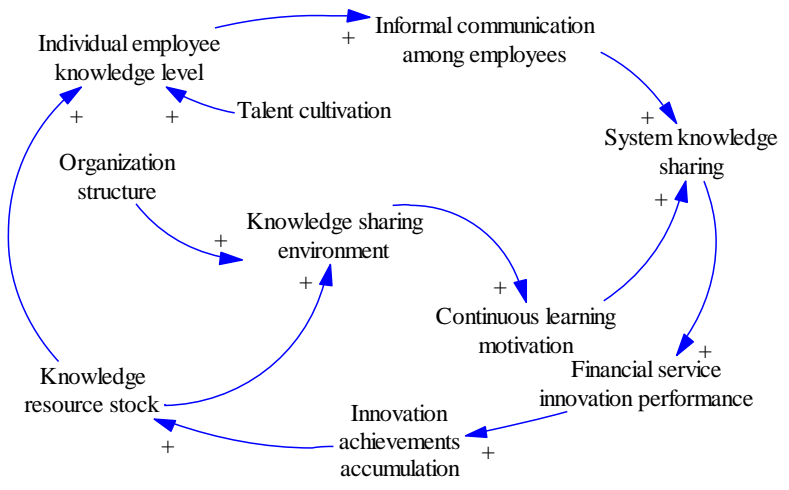

Figure 3. Causality diagram of knowledge development subsystem based on Financial Service Innovation.

As can be seen in Fig. 3, the main feedback loops in the causality diagram are:

- Knowledge resource stock $\rightarrow$ individual employee knowledge level $\rightarrow$ informal communication among employees $\rightarrow$ system knowledge sharing $\rightarrow$ financial service innovation performance $\rightarrow$ innovation achievements accumulation $\rightarrow$ knowledge resource stock.

- Knowledge resource stock $\rightarrow$ knowledge sharing environment $\rightarrow$ continuous learning motivation $\rightarrow$ system knowledge sharing $\rightarrow$ financial service innovation performance $\rightarrow$ innovation achievements accumulation $\rightarrow$ knowledge resource stock.

As can be seen in Fig. 4, the main feedback loops in the causality diagram are:

- Knowledge resource stock $\rightarrow$ economic and social benefits $\rightarrow$ market internationalization degree $\rightarrow$ new technology perception ability $\rightarrow$ innovation technology level $\rightarrow$ knowledge application efficiency $\rightarrow$ financial service innovation performance $\rightarrow$ innovation achievements accumulation $\rightarrow$ knowledge resource stock. 
- Knowledge resource stock $\rightarrow$ information processing mechanism $\rightarrow$ knowledge feedback speed $\rightarrow$ knowledge application efficiency $\rightarrow$ financial service innovation performance $\rightarrow$ innovation achievements accumulation $\rightarrow$ knowledge resource stock.

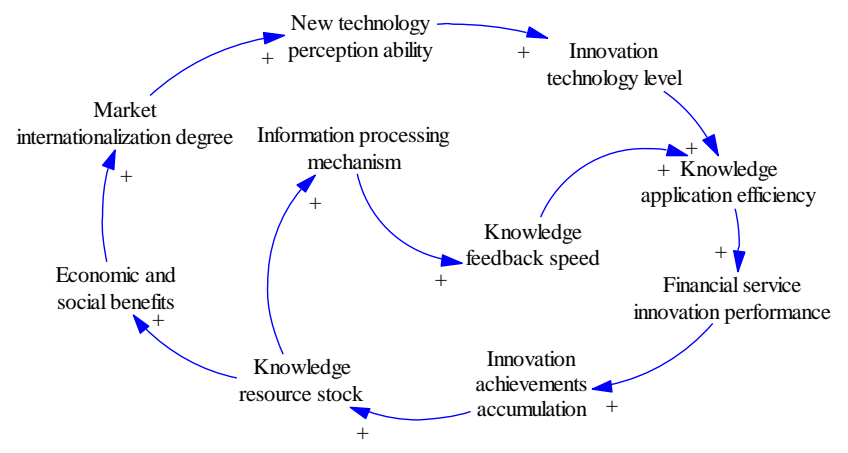

Figure 4. Causality diagram of knowledge application subsystem based on Financial Service Innovation.

Based on the causality analysis of the knowledge creation, development and application subsystem based on financial service innovation, the system's complete causality diagram is shown in Fig. 5.

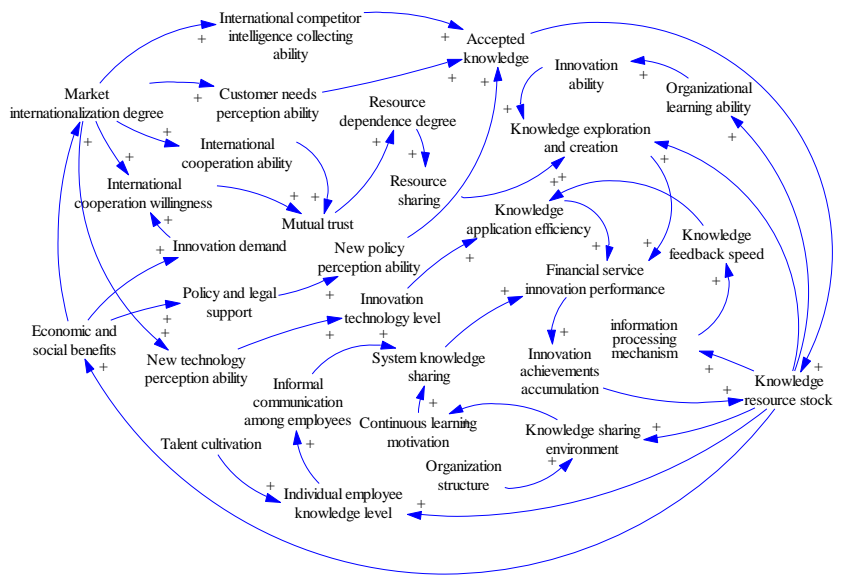

Figure 5. Causality diagram of knowledge management system based on Financial Service Innovation.

\section{System Flow Diagram}

According to the results of causality analysis, the flow chart model of knowledge management system based on financial service innovation is constructed in Fig. 6. It contains 2 state variables, 2 flowrate variables, 27 auxiliary variables and 2 constants, as shown in Table 1.

The 2 state variables, knowledge resource stock(KRS) and financial service innovation performance(FSIP) are used to measure the overall knowledge level and the performance level of the whole innovation process. Among them, KRS is affected by innovation achievements accumulation (IAA) and accepted knowledge (AK). FSIP is affected by three aspects: Knowledge exploration and creation(KEC), system knowledge sharing (SKS) and knowledge application efficiency (KAE).

TABLE I. VARIABLES AND CONSTANTS IN THE SYSTEM FLOW DIAGRAM

\begin{tabular}{|c|c|}
\hline $\begin{array}{l}\text { Variable } \\
\text { type }\end{array}$ & Variable name \\
\hline $\begin{array}{c}\text { State } \\
\text { variable }\end{array}$ & $\begin{array}{l}\text { Knowledge resource stock(KRS), } \\
\text { financial service innovation performance(FSIP) }\end{array}$ \\
\hline $\begin{array}{l}\text { Flowrate } \\
\text { variable }\end{array}$ & $\begin{array}{l}\text { Knowledge resource stock increment(KRSI), } \\
\text { financial service innovation performance increment(FSIPI) }\end{array}$ \\
\hline $\begin{array}{l}\text { Auxiliary } \\
\text { variable }\end{array}$ & $\begin{array}{l}\text { Market internationalization degree(MID), international } \\
\text { competitor intelligence collecting ability(ICICA), customer } \\
\text { needs perception ability(CNPA), international cooperation } \\
\text { ability(ICA), resource dependence degree(RDD), accepted } \\
\text { knowledge(AK), innovation ability(IA), resource } \\
\text { sharing(RS), knowledge exploration and creation(KEC), } \\
\text { organizational learning ability(OLA), mutual trust(MT), } \\
\text { international cooperation willingness (ICW), new technology } \\
\text { perception ability (NTPA), new policy perception ability } \\
\text { (NPPA), innovation demand (ID), knowledge application } \\
\text { efficiency (KAE), economic and social benefits (ESB)、 } \\
\text { policy and legal support (PLS), innovation technology } \\
\text { level(ITL), system knowledge sharing (SKS), information } \\
\text { processing mechanism (IPM), knowledge feedback speed } \\
\text { (KFS), individual employee knowledge level (IEKL), } \\
\text { informal communication among employees (ICE), } \\
\text { continuous learning motivation (CLM), knowledge sharing } \\
\text { environment(KSE), innovation achievements accumulation } \\
\text { (IAA) }\end{array}$ \\
\hline Constant & Talent cultivation(TC), organization structure(OS) \\
\hline
\end{tabular}

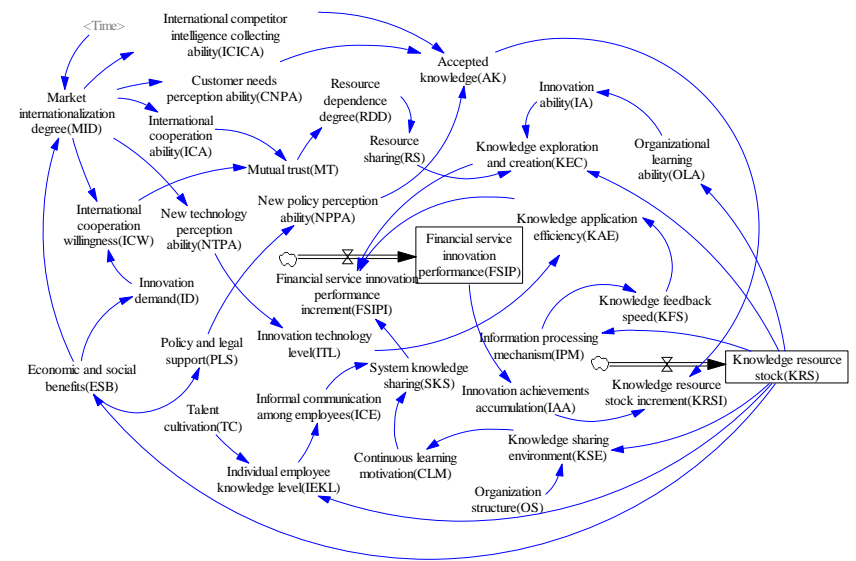

Figure 6. Knowledge management system flow chart based on Financial Service Innovation.

\section{Model SimUlation AND ANALYSIS}

According to the logic relation of each variable constructed by the system flow chart, the SD method is used to verify the validity and accuracy of the model. Before model simulation, the design of simulation equation is needed. The Vensim software is used to simulate the system, and the relevant parameters are obtained according to the relevant data of commercial banks in the FTZ District of Shanghai. The simulation time is set as one year. 


\section{A. The Design and Description of the Main Simulation Equations}

According to the relationship shown in Fig. 6, the equations and the initial values of the model are set up (Table 2). Among them, market internationalization degree (MID) is set as a table function changed by time, with the trend of change from slow growth to gradually increasing until saturation. Policy and legal support (PLS) is often affected by economic and social benefits, which is simulated by a sine function. As for mutual trust (MT), due to the establishment of trust between enterprises would be carried out after long-term cooperation, delay function DELAY1I is proper with the delay of two units. The company's resource dependence degree (RDD) will generally not higher than 0.6, which is set as IFTHENELSE function. The other variables are composed of the direct factors and their corresponding weights $(\beta)$, which are assessed by experts. The initial values of all equations are set to 0 and the two constants (TC, OS) are set to 80 .
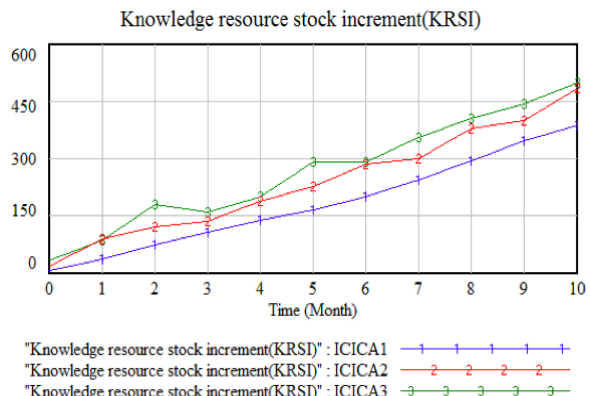
"Knowledge resource stock increment(KRSI)" : ICICA3 3

Figure 7. The impact of ICICA on KRS and FSIP.

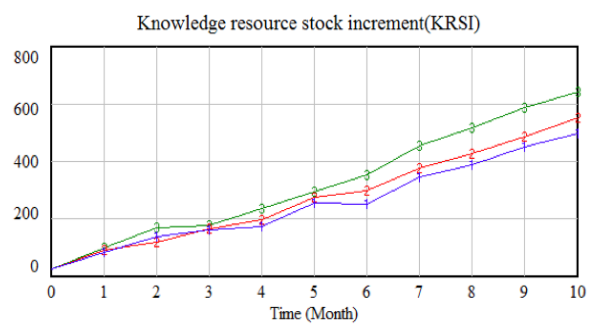

"Knowledge resource stock increment(KRSI)" : TC1 $+1,1,1,1+$ "Knowledge resource stock incremen(KRSI": : $1 C 2 \begin{array}{llllll}2 & 2 & 2 & 2 & 2 & 2\end{array}$ "Knowledge ressurce stock incenent(KRS)" : TC3

Figure 8. The impact of TC on KRS and FSIP.

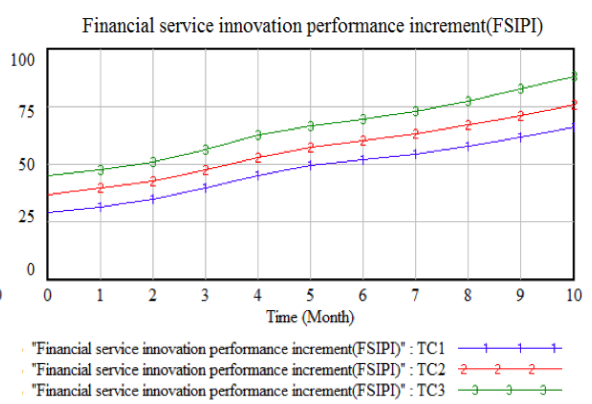

\begin{tabular}{|c|c|}
\hline$K R S=I N T E G(K R S I, 0)$ & $P L S=1+\operatorname{SIN}\left(6 \beta_{R L S} \cdot E S B\right)$ \\
\hline$K R S I=A K+I A A$ & $K A E=\beta_{\text {KIEX }} \cdot K F S+\beta_{\text {KIEI }} \cdot I T L$ \\
\hline$F S I P=I N T E G(F S I P, 0)$ & $E S B=\beta_{E x} \cdot K R S$ \\
\hline$F S I P I=K E C+S K S+100 \cdot K A E$ & $N T P A=\beta_{\text {MTPA }} \cdot M I D$ \\
\hline$K E C=\left(\beta_{x a c x} \cdot R S+\beta_{x a \sigma} \cdot L A+\beta_{x E C K} \cdot K R S\right) \cdot 100$ & \multirow{3}{*}{$\begin{array}{l}\text { MID = WITHLOOKUP }(\text { Time },([(0,0)-(5,1)],(0,0.2) \\
,(0.5,0.23),(1,0.42),(1.5,0.6),(2,0.78),(2.5,0.89) \\
,(3,0.93),(3.5,0.94),(4,0.95),(4.5,0.96))) \cdot \beta_{\text {MD }} \cdot \text { ESE }\end{array}$} \\
\hline$K S E=\beta_{K E x} \cdot K R S+\beta_{K E D} \cdot O S$ & \\
\hline$S K S=\left(\beta_{\text {SSCC }} \cdot C L M+\beta_{S K S} \cdot I C E\right) \cdot 100$ & \\
\hline$I C W=\beta_{x \pi N} \cdot M I D+\beta_{x \pi 7} \cdot I D$ & $L A A=\operatorname{INTEG}(F S I P, 0)$ \\
\hline$A K=\left(\beta_{\triangle I E} \cdot I C I C A+\beta_{\triangle I C} \cdot C N P A+\beta_{\triangle I E} \cdot N P P A\right) \cdot 100$ & $M T=D E L A Y 1 I\left(\beta_{M a A} \cdot I C A+\beta_{\text {Mat }} \cdot I C W, 2,0\right)$ \\
\hline$I E K L=\beta_{\text {IRZI }} \cdot T C+\beta_{\text {IXXX }} \cdot K R S$ & $R D D=I F T H E N E L S E\left(\beta_{R D D} \cdot M T<0.6, \beta_{R D D} \cdot M T, 0.6\right)$ \\
\hline
\end{tabular}

\section{B. Simulation Results Analysis}

The above equations and some parameters are input into Vensim software and the simulation results are shown in Fig. 7- Fig. 9. The results show the performance of KRS, FSIP and the effect of each factor during simulation time. The overall results are in line with the actual situation.

Financial service innovation performance increment(FSIPI)

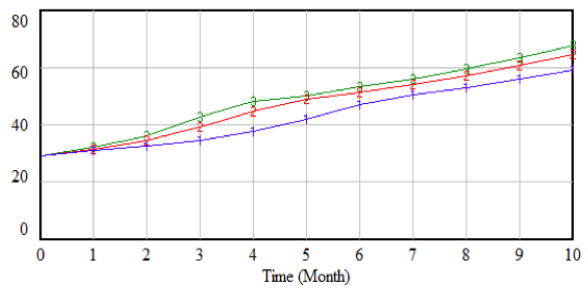

"Financial service innovation performance increment(FSIPI") : ICICA1 +4 "Financial service innovation performance increment(FSIPI" : ICICA2 $2 \mathrm{2}_{2}^{2}$

stock increment(KRSI)

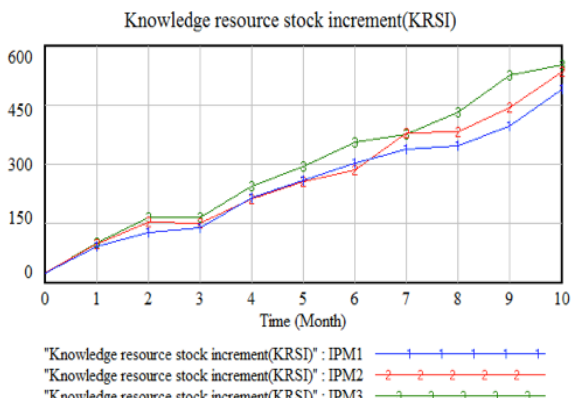

Financial service innovation performance increment(FSIPI)

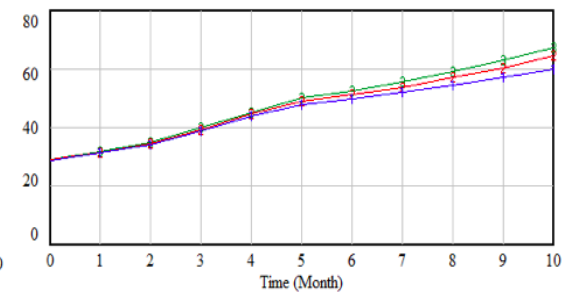

', "Financial service innovation performance increment(FSIPP)": IPM1

- "Financial service innovation performance increment(FSIPI)" : IPM3

Figure 9. The impact of IPM on KRS and FSIP. 
The following conclusions can be drawn from the simulation results:

In the whole process of financial service innovation, knowledge resource stock(KRS) and financial service innovation performance(FSIP) are increasing. This is because with the increasing trade volume in Shanghai FTZ, the knowledge interaction between commercial banks and outside foreign keeps increasing. With the continuous expansion of knowledge sources, it provides a steady stream of power for knowledge creation, sharing and application, which leads to the accumulation and creation of financial service innovation.

In the knowledge creation process, international competitor intelligence collecting ability(ICICA), customer needs perception ability(CNPA), international cooperation ability(ICA) and new policy perception ability (NPPA) all have a significant positive effect on KRS and FSIP. For instance, with the increase of ICICA(Fig. 7), both of them are significantly improved but the speed of KRSI is faster, which proofs the chain structure in conceptual model of "ICICA $\rightarrow$ KRS $\rightarrow$ FSIP". They show that the international market environment requires commercial banks have a more sharp perception of external knowledge environment changes, including diversified customer groups, peer competitors, cooperative enterprises, and varying policy environment. The knowledge interaction with the above subjects can provide commercial banks with time - effective knowledge. Therefore, there are four aspects that the state-owned commercial can improve:

- Promote customer communication to understand the individual needs of different customers.

- Strengthen the information sensitivity of peer competitors.

- Strengthen the knowledge interaction with cooperative enterprises.

- Improve the sensitivity of external policy environment change.

In the stage of knowledge sharing, individual employee knowledge level (IEKL) and knowledge sharing environment(KSE) have significant influence on FSIP. Taking IEKL as an example (Fig. 8), a good talent training can improve the knowledge level of the employees which increase the possibility to create new knowledge. Similarly, a reasonable organizational structure can promote the atmosphere of knowledge sharing and increase the frequency of knowledge interaction. Therefore, commercial banks need to pay more attention to personnel training and organizational structure by trying to select employee with high knowledge level and organizing regular knowledge training for employees. At the same time, they need to improve the organizational structure to expand the internal knowledge flow channels, to provide the structural basis for financial services innovation activities.

In the stage of knowledge application, new technology perception ability (NTPA) and information processing mechanism (IPM) have a significant impact on FSIP. Taking TPM as an example (Fig. 9), the enhancement of TPM promotes the obvious improvement of FSIEI and KRSI. This is because the international competitive environment in
Shanghai FTZ urges commercial banks to improve information processing mechanism continuously, in order to carry out complete knowledge activities. At the same time, they need to improve the perception of new technology, with which provide a platform foundation for the promotion of financial services.

\section{SUMMARY}

In this paper, we use the method of system dynamics to research the knowledge management process model based on financial service innovation. Starting from the three main activities of knowledge management, knowledge creation, knowledge sharing and knowledge application, combining with the features of commercial banks in Shanghai FTZ, analyze the main influence factors of financial service innovation at each stage. It not only enriches the application scope of knowledge management, but also makes a deep research on the field of financial service innovation. This model is reasonable and effective. With its simulation results, the policy recommendations can improve financial service innovation performance of the state-owned commercial banks in Shanghai FTZ, which has important practical significance.

Because of the complexity of some elements in knowledge management, some of the factors in this paper do not reflect the dynamic characteristics in reality, and the description of the relationship between the relevant elements is simplified. Therefore, the complexity of their relationship needs to be further studied.

\section{ACKNOWLEDGMENT}

Research for this article was funded by Jiangxi Provincial Department of Education under the project of "The design of knowledge management mechanism based on Financial Service Innovation: a case study of Shanghai FTZ" (Contract Number 35989930).

\section{REFERENCES}

[1] Ian Miles, Nikos Kastrinos, Rob Bilderbeek, Pim den Hertog, Kieron Flanagan, Willem Huntink and Mark Bouman. Knowledge-intensive business services. Users, carriers and sources of innovation[J]. Second National Knowledge Infrastructure, 1998, 44(4):100-128.

[2] Yao D, Whalley J. The China (Shanghai) Pilot Free Trade Zone: Background, Developments and Preliminary Assessment of Initial Impacts[J]. World Economy, 2015, 39(472).

[3] ShuHua Chien, Jyhjye Chen. Supplier involvement and customer involvement effect on new product development success in the financial service industry[J]. Service Industries Journal, 2010, 30(2):185-201.

[4] Wan Z, Zhang Y, Wang X, et al. Policy and politics behind Shanghai's Free Trade Zone Program[J]. Journal of Transport Geography, 2014, 34(Complete):1-6.

[5] Alavi M, Leidner D E. Review: Knowledge management and knowledge management systems: conceptual foundations and research issues[J]. Mis Quarterly, 2001, 25(1):107-136.

[6] Blazevic V, Lievens A. Learning during the new financial service innovation process : Antecedents and performance effects[J]. Journal of Business Research, 2004, 57(4):374-391.

[7] Dawson R. Developing knowledge-based client relationships: the future of professional services[M]. Burlington: Butterworth Heinemann, 2000:25. 
[8] Burkelc T. The Internationalisation of Foreign Financial Service Companies in China: The Importance of Strategic Alliances between Foreign and Chinese Domestic Banks[J]. Bulletin of the World Health Organisation, 2011, 89(1):41-5.

[9] Abbasi G, Najafi A. Relationship between the use of Knowledge management and employee performance in an organization (case study of General Governor Office of Zanjan)[J]. Bericht Über Die Zusammenkunft Deutsche Ophthalmologische Gesellschaft, 2014, 70(2):365-378.

[10] Wagner H T, Wagner D, Vollmar G. The impact of information technology on knowledge creation[J]. Journal of Enterprise Information Management, 2014, 27(1):31 - 44. 